\title{
HbA1c: Point of Care Testing in Control of Type-2 Diabetes Mellitus in Population of Nowshera, Pakistan
}

Hamzullah Khan, ${ }^{1}$ Muhammad Basharat Khan, ${ }^{1}$ Shabir Hussain, ${ }^{1}$ Saiqa Zahoor, ${ }^{2}$ Muhammad Asif, ${ }^{3}$ Shahtaj Khan ${ }^{2}$

\begin{abstract}
Background: Diabetes mellitus is a highly prevalent non-communicable disease with a further implication of the development of life-threatening diseases like cardiovascular disease and stroke.

Objective: To determine the glycosylated hemoglobin levels utility in assessing the point of care testing in the control of diabetes mellitus in the population of Nowshera in a hospital-based study.

Methodology: This was a cross-sectional study, conducted in the department of Pathology in collaboration with the Department of General Medicine, Qazi Hussain Ahmed Medical Complex, Nowshera, from 30 February 2019 to January 2020. Descriptive statistic was used for describing the variables. A Chi-square test was used for the association of Hba $1 \mathrm{c}$ in gender groups. SPSS version 25 was used for data analysis.

Results: Out of the total 119 patients, $44(37 \%)$ were males and $75(63 \%)$ were females. The mean age with standard deviation was $53 \pm 9.5$. The Mean Hbalc with standard deviation was $10.53 \pm 2.38$. Sixty-eight (57.1\%) of the patients were in the age range 46-60 years. Eighty-eight (73.9\%) were poorly controlled diabetics with Hbalc of $>9 \%$. Using the chi-square test it was observed that gender has no significant impact on the severity of the disease $(p=0.38)$. The relative risk of female gender and for age $>50$ years was $(R R=1.11)$.

Conclusion: We observed that the majority of the patients had poorly controlled diabetes with $\mathrm{Hba} 1 \mathrm{c}>9 \%$ which is an alarming situation. Age and gender play a very important role in the prognosis of diabetes mellitus.

Keywords: Diabetes mellitus, Glycosylated hemoglobin, Glycemic control.

Article Citation: Khan H, Shabir H, Khan MB, Zahoor S, Asif M, Khan S. Hba1c: Point of Care Testing in Control of Type-2 Diabetes Mellitus in Population of Nowshera. JSZMC 2021;12(1):17-21. DOI: https://doi.org/10.47883/jszmc.v12i1.95
\end{abstract}

This Open Access article in Journal of Sheikh Zayed Medical College is licensed under a Creative Commons Attribution-NonCommercial 4.0 International License.

\section{Introduction}

Diabetes Mellitus affecting a huge population of all age groups, with alarming global prevalence irrespective of gender, ethnicity, and habitat. ${ }^{1}$ A diabetes prevalence survey published in British Medical Journal regarding Pakistan based on Hbalc data covering 18856 eligible participants, reported the prevalence of Type 2 diabetes in $16.98 \%$ population. Pre-diabetes was also reported to be prevalent in $10.9 \%$ of the target population. ${ }^{1}$ The prevalence in age categories was highest in age $51-60$ years of age as $26 \%(95 \% \mathrm{CI})$, in class-III obese $(35 \%)$, with a family history of DM (31\%), and in female gender $(17.8 \%){ }^{1,2}$ Hence the recent prevalence data suggests a higher rate of pre-diabetes in the country much higher than the previously reported studies. ${ }^{1,2}$

A study reported shows Pakistan ranking at $7^{\text {th }}$ position within the high burden countries worldwide and is expected to jump to position four if the condition remains unnoticed by the decisionmakers. ${ }^{3}$ Glycosylated hemoglobin (HbAlc) is a standard marker that measures the blood glucose levels of the last 4-6 weeks. HbAlc measures the glycemic status and is more sensitive and specific than random or fasting readings. ${ }^{4}$ The higher percentage of $\mathrm{HbAlc}$ refers to poor glycemic control.

Available literature shows that every $1 \%$ drop in the HbA1c has a strong clinical association with a significant reduction in case fatality risk associated with diabetes mellitus. ${ }^{5}$ Every $1 \%$ drop in $\mathrm{HbAlc}$ reduces the chances of myocardial infarction by $14 \%$ and decreases the risk of cerebrovascular complications by $37 \% .^{6,7}$ The Glycosylated Hemoglobin (HbA1c), over the last two decades has

1.Nowshera Medical College, Nowshera, Pakistan

2.Post Graduate Medical Institute(PGMI) HMC, Peshawar, Pakistan

3.Gajju Khan Medical College Swabi, Pakistan.

Correspondence: Dr. Hamzullah Khan, Professor of Hematology, Nowshera Medical College, Nowshera, Pakistan.

Email: hamzakmc@gmail.com

Received: $25-06-2020$

Published: 11-05-2021 
become the gold standard test to monitor the glucose level in diabetics. ${ }^{8}$ The levels of HbAlc are directly related to the risk for complications associated with diabetes. ${ }^{9}$ HbA1c levels vary in gender, age categories, and ethnic groups in the healthy population. Therefore, there are recommendations that each region should establish its reference range for the $\mathrm{HbAlc}$ for non-diabetic, pre-diabetes, and diabetes. ${ }^{10}$

The number of tests of $\mathrm{HbA} 1 \mathrm{c}$ is a measure of quality control of diabetes. The frequency of diabetic patients with one or more HbAlc tests per year was $91 \%$ and the same in the poorly controlled category was $27 \%(p=0.05))^{11}$ Present study was therefore designed to determine the glycosylated hemoglobin levels utility in assessing the point of care testing in the control of diabetes mellitus in the population of Nowshera in a hospital-based study.

\section{Methodology}

A cross-sectional study was conducted in Pathology Department from February 2019 to January 2020. We determined the sample size of 119 using open-epi software with a margin of error at $(5 \%)$, Confidence level at $95 \%$, taking the anticipated mean of Hbalc at $6.62 \%$ from the diabetes prevalence survey of Pakistan, keeping drop out at $10 \%$ to estimate the true population. Ethical approval was sought out from the Ethical Committee of the Medical Teaching Institue, Nowshera Medical College/QHAMC, Nowshera. The inclusion criteria were all known diabetic patients received in the Pathology department for HbA1c testing, irrespective of age and gender. While the exclusion criteria were all patients with co-morbidities and those who were already on insulin therapy were also excluded. Similarly, terminally ill diabetic patients or patients with cognitive disorders due to complications were also excluded from the study.

Two milliliters of blood was taken in an EDTA tube using aseptic techniques by venipuncture. HbA1c test was performed on Roche Cobas E411 Chemistry Analyzer. Calibration was done as per the instructions of the manufacturer.

Patients were grouped/categorized on the basis of HbA1c levels as per guidelines; ${ }^{1}$ Non-diabetic, 45.9\%, Good control Diabetes, 6-7\%, Fair control diabetes, 7.1-8.9\%, and Poorly controlled diabetes as $>9 \%$.
Necessary information was recorded in SPPS Version $25^{\text {th }}$ designed as per the objectives of the study. Chi-square test was used for categorical variables in gender groups. Descriptive statistic was used for describing variables like age and HbAlc levels. The Odds Ratio was calculated for stratification of age and gender categories to enumerate the risk factors for poorly controlled diabetes using risk analysis statistics.

\section{Results}

Out of the total 119 patients, 44 (37\%) were males and $75(63 \%)$ were females. The age of patients was from 12 years to 75 years with a mean and standard deviation of age as $53 \pm 9.5$ years. The mode of age was 45 years. The mean with a standard deviation of the $\mathrm{HbA1c}$ was $10.53 \pm 2.38$. The minimum $\mathrm{HbA1c}$ recorded was $4.8 \%$ with a maximum of $15 \%$ and a range of $10.2 \%$.

The distribution of the HbAlc among diabetic patients was normally distributed. (Figure-I)

Figure-I: Distribution of HbA1c among diabetes patients.

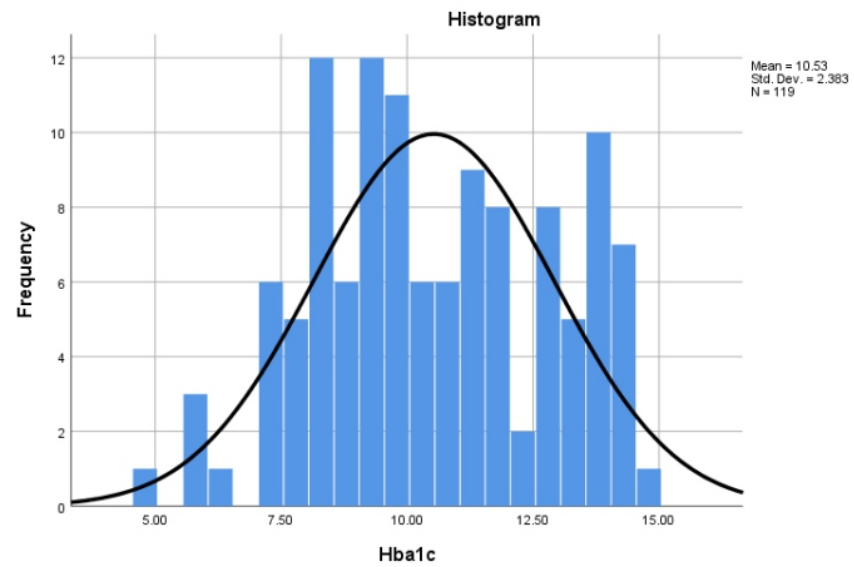

We also applied the Kolmogorov-Smirnov test (Sample $>50$ ) to show the normality of data and observed an insignificant p-value of 0.2 , representing that data is normally distributed. (Table-I)

Table-I: Tests of Normality on HbA1c Distribution

\begin{tabular}{|c|c|c|c|c|}
\hline \multirow{2}{*}{ Variable } & \multirow{2}{*}{ Gender } & \multicolumn{3}{|c|}{ Kolmogorov-Smirnov } \\
\hline & & Statistic & Df & Sig. \\
\hline \multirow{2}{*}{ Hba1 } & Male & .097 & 44 & .2 \\
\hline & Female & .116 & 75 & .015 \\
\hline
\end{tabular}


It was astonishing to note that $88(73.9 \%)$ out of 119 were poorly controlled diabetics with $\mathrm{HbA1c}$ $>9 \%$. Similarly, $26(21.8 \%)$ were having fairly controlled diabetes with $\mathrm{HbA}$ lc between 7.1 to $8.9 \%$. Only $4(3.4 \%)$ patients had good control of diabetes with $\mathrm{HbA} 1 \mathrm{c}$ between 4 to $5.9 \%$ at the first appointment. (Table-II)

Table-II: Diabetes Control Categories based on HbA1c.

\begin{tabular}{|l|c|c|}
\hline $\begin{array}{l}\text { Diabetes Control } \\
\text { Category }\end{array}$ & Frequency & Percent \\
\hline Non-diabetic & 1 & 0.8 \\
\hline $\begin{array}{l}\text { Good control } \\
\text { (4-5.9\%) }\end{array}$ & 4 & 3.4 \\
\hline $\begin{array}{l}\text { Fair control } \\
\text { (7.1-8.9\%) }\end{array}$ & 26 & 21.8 \\
\hline $\begin{array}{l}\text { Poor control } \\
\text { (>9\%) }\end{array}$ & 88 & 73.9 \\
\hline Total & 119 & 100 \\
\hline
\end{tabular}

We divided the patients into the age categories and observed that $68(57.1 \%)$ of the patients were in the age range $46-60$ years, followed by $27(22.7 \%)$ in the age range $31-45$ years, $23(19.3 \%)$ in the age group of $>60$ years, and only $1(0.8 \%)$ in the age group 12-30 years.

We used the categorical variables (gender vs HbA1c categories) and assessed the association between the categories. Apparently, it seemed that the female gender dominated the poorly controlled diabetes category but at a 95\% Confidence interval using the chi-square test this association was not statistically significant at a p-value 0.3 . (Table-III)

Table-III: Association of gender with Diabetes Control

\begin{tabular}{|l|c|c|c|c|c|}
\hline \multicolumn{2}{|c|}{ HbA1c vs Gender } & \multicolumn{2}{|c|}{ Gender } & \multirow{2}{*}{ Total } & \multirow{2}{*}{$\begin{array}{c}\text { P- } \\
\text { value }\end{array}$} \\
\cline { 2 - 5 } & Male & Female & & \\
\hline \multirow{3}{*}{$\begin{array}{l}\text { HbA1c } \\
\text { Category }\end{array}$} & Non-diabetic & 0 & 1 & 1 & \\
\cline { 2 - 5 } & Food control & 0 & 4 & 4 & \multirow{2}{*}{0.324} \\
\cline { 2 - 5 } & Fair control & 10 & 16 & 26 & \\
\hline Total & Poor control & 34 & 54 & 88 & \\
\hline
\end{tabular}

We cross-tabulated the gender with two categories of the HbAlc (Hbalc $\leq 9$, and Hbalc $\geq 9.1)$ to find the Odds Ratio of gender in poor control of diabetes. It was obtained from the analysis that the female gender was a Risk factor with a value of 1.11 that is greater than 1 . Then we cross-tabulated the age categories $(\leq 50$ years, and $>50$ years of age $)$ with two categories of the HbAlc (Hbalc $\leq 9$, and Hbalc $\geq 9.1$ ) to find the Odds Ratio of advancing age in poor control of diabetes. It was obtained from the analysis that age category 2 that is more than 50 years of age was a risk factor with a value of 1.01 that is greater than 1 .

\section{Discussion}

Type 2 diabetes mellitus is a metabolic disorder, which is characterized by hyperglycemia has a strong association with renal, ophthalmic, and neuropathic attributed to its microvascular complications. Likewise, macrovascular complications include cardiovascular and cerebrovascular complications. Many studies have reported HbAlc as the gold standard for diabetes. The volume of $\mathrm{HbA1c}$ has dramatically increased over the past few decades globally, and many researchers have attempted to determine how the test should be performed and how to interpret for specific geographical areas under study. ${ }^{8,912}$ In the present study, we observed a maximum number of patients $85 / 119(71.42 \%)$ were registered for the purpose of provision of free insulin in social welfare program initiated by the administration of QHAMC. The rest of the patients visited the outdoor department. The age range of patients was from 12 years to 75 years, with mean age with a standard deviation of $53 \pm 9.5$ years. The mean with a standard deviation of the HbAlc was $10.53 \pm 2.38$. The present study comprised mainly of diabetic patients and we aimed to determine the diabetic control using $\mathrm{HbA} 1 \mathrm{c}$ as a tool for validation of our objectives. It was astonishing to note that 88 (73.9\%) out of 119 were poorly controlled diabetics with Hba1c of $>9 \%$. Similarly, $26(21.8 \%)$ were having fairly controlled diabetes with Hba1c between 7.1 to $8.9 \%$. Similar findings have been reported in a study reported from Ghana, where they reported the prevalence of diabetes as $13.6 \%$ with $86.5 \%$ of the diabetic with poorly controlled glycemic levels. ${ }^{13}$ We observed female gender predominance in poorly controlled diabetics. Out of the total 119 patients, $44(37 \%)$ were males and 75 $(63 \%)$ were females. Abid S et $\mathrm{al}^{14}$ from Agha Khan 
University Karachi reported in a trial on the prevalence of diabetes that female gender predominance was observed in both symptomless and complicated diabetes groups. We also find our statistics consistent with Kerman Coronary Artery Disease Risk Study (KERCADRS) reports published in the International Journal of Health Policy Management, that the mean level of $\mathrm{HbA} 1 \mathrm{c}$ in total subjects was $8.56 \pm 4.72 \%$ and only $31.66 \%$ of males and $26 \%$ of females had acceptable levels of HbA1c. ${ }^{15}$ A local study reported the mean $\mathrm{HbA} 1 \mathrm{c}$ in their target population as 9.3\%, which coincides with our findings. ${ }^{16}$

We observed that $68(57.1 \%)$ of the patients were in the age range of 46-60 years, followed by 27 $(22.7 \%)$ in the age range of $31-45$ years. Our findings are supported by Diabetes prevalence survey of Pakistan that was executed in MTI Hayatabad Medical complex, Department of Endocrinology, Government of Khyber Pakhtunkhwa, and department of Public Health Khyber Medical University in collaboration with the University of Manchester UK and Pakistan Endocrine Society from April 2017 to November 2017, that showed the highest prevalence in the age range $51-60$ years $(26.03 \%, \mathrm{p}<0.001)$. ${ }^{1}$ The mean age was 45.23 years (SD 13.97 years) in the Diabetes prevalence survey of Pakistan that was lower than our findings of $53+9$ years. We divided our patients in $\mathrm{Hb} 1 \mathrm{c}$ categories $(\mathrm{HbAl} \leq \mathrm{c}$, and HbAlc >9.1) to find the Odds Ratio of gender in poor control of diabetes. We observed that the female gender has an Odds Ratio with a value of 1.11 that is greater than 1 , and almost similar results were found for age $>50$ years. Our findings were supported by many authors that female gender especially in the age range 45-60 years are at high risk of diabetes with accomplished poor control. $^{14-16,1,10}$ Diabetes has very serious implications on life expectancy. This depends on the various factors like age of the patient, gender, how soon one can receive diagnosis and treatment, and last but not least that how is he/she managed for the poorly controlled diabetes. ${ }^{17}$

\section{Conclusion}

It was concluded that the majority of the patients had poorly controlled diabetes with $\mathrm{HbAlc}>9 \%$. Age and gender play a very important role in the prognosis of diabetes mellitus. Female gender and age more than 50 years function as risk factors of poorly control of diabetes mellitus in our setup, so it may affect mean and median survival time in poorly controlled diabetes. Therefore the physician should pay more attention to diabetic patients with age more than 50 years, female gender in addition to the duration of disease for more than 10 years, those are more at risk to develop complications and comorbidities to meet the worst outcome with the end of lives.

Authors Contribution: HK: Conception of work, design of work and revising. MBK: Acquisition and analysis of data and drafting. SH: Conception, interpretation of data and drafting. SZ: Conception, acquisition and analysis of data and drafting. MA \& SK: Conception, interpretation of data and drafting. All authors critically revised and approve its final version.

Conflict of Interest: Author has declared no conflict of interest.

Sources of Funding: The source of funding was self. Disclaimer: None

\section{References}

1. Aamir AH, Ul-Haq Z, Mahar SA, Qureshi FM, Ahmad I, Jawa A et al. Diabetes Prevalence Survey of Pakistan (DPS-PAK): Prevalence of type 2 diabetes mellitus and prediabetes using HbAlc: a population-based survey from Pakistan. BMJ Open 2019;9:e025300. doi: 10.1136/bmjopen-2018-025300

2. Jawaid S, Nadeem SG. Prevalence and Risk factors for Diabetes mellitus in Urban Population of Karachi (A Short Study). J Pak Med Assoc 2013;4 (2):64-6.

3. Khuwaja AK, Fatmi Z, Soomro WB, Khuwaja NK. Risk factors for cardiovascular disease in school children: a pilot study. J Pak Med Assoc, 2003; 53: 396-400

4. Akinloye OA, Adaramoye OA, Akinlade KS, Odetola AA, Raji AA. Relationship between fasting Plasma Glucose and Glycated Hemoglobin in Adult Diabetic Nigerians. African Journal of Biomedical Research 2007;10:127-32.

5. Maureen, Harris MI. Frequency of blood glucose monitoring in relation to glycemic control in patients with type 2 diabetes. Diabetes Care 2001; 24: 979-82.

6. World Health Organization. (Online). Diabetes Control. Available from: https://applications.emro.who.int/ dsaf/dsa664.pdf

7. Badruddin N, Basit A, Hydrie MZI, Hakeem R. Knowledge, Attitude and Practices of Patients Visiting a Diabetes Care Unit. Pakistan Journal of Nutrition Asian Network for Scientific Information 2002: 99-102.

8. Consensus Committee. Consensus statement on the Worldwide Standardization of the hemoglobin A1C measurement. Diabetes care 2007; 30:2399-400. 
9. Little RR, Roberts WL. A Review of Variant Hemoglobins Interfering with Hemoglobin A1c Measurement. J Diabetes Sci Technol 2009;3(3):44651.

10. David BS. Carbohydrates. In: Burtis CA, Ashwood ER. Tietz textbook of clinical chemistry and Molecular Diagnostics, 4th ed. St. Louis: Saunders, 2006:837-901.

11. King H, Aubert RE, Herman WH. Global burden of diabetes, 1995-2025. Diabetes Care. 1998;21:14141431

12. Lyon AW, Higgins T, Wesenberg JC, Tran DV, Cembrowski GS. Variation in the Frequency of Hemoglobin A1c (HbA1c) Testing: Population Studies Used to Assess Compliance with Clinical Practice Guidelines and Use of HbA1c to Screen for Diabetes. Journal of Diabetes Science and Technology 2009: 3(3): 411-7.doi.org/ $10.1177 / 193229680900300302$

13. Opong J, Takramah W, Axame WK, Owusu R, Parbey PA, Adjuik M, Tarkang E. Prevalence of controlled and uncontrolled diabetes mellitus and associated factors of controlled diabetes among diabetic adults in the hohoe municipality of Ghana. Diabetes Manag,(2017); 7(5):343-354.
14. Abid S, Jafri W, Jahan F, Rabbani F, Islam N, Khan M, et al. Poor glycaemic control is the major factor associated with increased frequency of gastrointestinal symptoms in patients with diabetes mellitus. Journal of Pakistan Medical Association 2007; 7(7): 345-9

15. Yousefzadeh G, Shokoohi M, Najafipour H. Inadequate control of diabetes and metabolic indices among diabetic patients: A population-based study from the Kerman Coronary Artery Disease Risk Study (KERCADRS). Int J Health Policy Manag 2015; 4(5): 271-277.

16. Basit A, Hydrie MZ, Hakeem R, Ahmedani MY, Waseem M. Glycemic control, hypertension and chronic complications in type 2 diabetic subjects attending a tertiary care center. J Ayub Med Coll Abbottabad 2005, 17: 63-68.

17. Lutgers HL, Gerrits EG, Sluiter WJ, Ubink-Veltmaat LJ, Landman GWD. Life Expectancy in a Large Cohort of Type 2 Diabetes Patients Treated in Primary Care (ZODIAC-10). PLoS One. 2009; 4(8): e6817. Published online 2009 Aug 28. doi: 10.1371/journal.pone.0006817 